\title{
Private Hospitals in Sylhet City, Bangladesh: An Issue of Service Marketing
}

\author{
Shamsu Uddin', Md. Mahbubur Rahaman', Md. Mazharul Islam ${ }^{3}$
}

${ }^{1}$ Department of Business Administration, Leading University, Sylhet, Bangladesh

${ }^{2}$ Department of Business Administration, Leading University, Sylhet, Bangladesh

${ }^{3}$ Department of Business Administration, Leading University, Sylhet, Bangladesh

\begin{abstract}
Competitive environment among the industrial and service sector has also influenced the healthcare especially hospitals in private sector. There is a tremendous growth in private hospitals during the last three decades, due to inadequate healthcare facilities available at public hospitals to meet the near about 160 million people of Bangladesh. This factor had provided an opportunity for the private hospitals to fill this gap by providing better healthcare services to the patients that leads to patient's satisfaction. This paper aimed to evaluate the service quality delivered by the private hospitals in Bangladesh based on patient's perception.
\end{abstract}

Keywords : Competitive; Healthcare; Hospitals; Private; Satisfaction. JEL Classification Code: M31; M39

\section{INTRODUCTION}

$\mathrm{M}$ ARKETING activity is not restricted only material goods. Marketing is also extended to service.Moreover, according to specialists, even though Marketing operates through tangible and intangible goods but importance of intangible goods are increasing day by day.

There is a prevailing proverb in our society 'Health is the source of all happiness.' In modern time health service has improved significantly which was previously absent. The health consciousness of people also increased as well. Once people died of Chicken pox and Diarrhoea which is now unconceivable. The reason behind this is the improvement in medical science. There are public hospitals in Bangladesh that provide health care to people almost free of cost. There are also private hospitals as well who have come to existence in order to fulfil the need of people.

The reality in Bangladesh is that, public hospitals are unable to provide quality health service to people. There is also scarcity of public hospitals in Bangladesh. That is what, which have triggered the establishment of private hospitals in Bangladesh. This has also created the opportunity of establishing private hospitals in Sylhet. Now in Sylhet metropolitan, there are about 30 private hospitals that are providing health service to people. Although, most of the people have negative perception about them they are an important part of health service sector of Sylhet city.

\section{History of Private Hospitals in BANGLADESH}

The objective of public hospitals is to provide health service to the people of all walks of life. But due to rapid increase in population and increase in health consciousness it has became impossible to provide appropriate health service to all. For this reason a private clinic was established in 1980s in Malibag of Dhaka. This type of private hospitals did not attract the eye of people before 1971. But during mid 1980s, there was seen a change in the number and structure of private hospitals.

Centralization of Private Hospitals in Bangladesh

It is found from a report that, there are almost 1000 small and large hospitals in Bangladesh. Among them about 70 hospitals and 250 clinics are situated in Dhaka city. In rest of the cities of Bangladesh like Sylhet we also have found mentionable hospitals and clinics. The number of hospitals and clinics in sylhet city nearly 50 .The reasons behind increase in number of private hospitals, that is, their centralization in cities are given below:

1. Increase in health consciousness of people.

2. Increased demand for health services.

3. Urbanization, that is, rapid extension of cities.

4. Migration of people toward city for jobs.

5. Perception of people about better income facility in city than rural area.

\section{LITERATURE REVIEW}

In 1972 the population of Bangladesh was 70 million. At present, it is more than 160 million. The population of Sylhet metropolitan is also increased thereby. But the hospitals required providing health service to them is much inappropriate. Due to having health consciousness people are not satisfied with general treatment; they seek improved health care. In this circumstance, private hospitals have appeared in front of the people to sell their health services.

Many studies have been conducted on the customer satisfaction and performance regarding hospital service. In one of the research regarding private hospitals carried 
out the view of sharma and chahal.Sharma and Chahal (1999) had done a study of patient satisfaction in outdoor services of private health care facilities. They had done a survey to understand the extent of patient satisfaction with diagnostic services. They have constructed a special instrument for measuring patient satisfaction. The instrument captures the behaviour of doctors and medical assistants, quality of administration, and atmospherics. The role of graphic characters like gender, occupation, education, and income is also considered. Based on their findings, they also suggested strategic actions for meeting the needs of the patients of private healthcare sector more effectively. In their study provided suggestions like becoming more friendly and understanding to the problems of patients, maintaining cleanliness in the units, both internally and externally, providing regular report regarding the patients' progress without waiting for them to demand, conducting surveys to know about the attitude of the patients with regard to the employees and adopting patient-oriented policies and procedures.

Sharma and Chahal (2003) stated that due to increased awareness among the people patient satisfaction had become very important for the hospitals. The authors examined the factors related to patient satisfaction in government outpatient services in India. They said that there are four basic components which had impact on the patient satisfaction namely, behaviour of doctors, behaviour of medical assistants, quality of atmosphere, and quality of administration. They also provided strategic actions necessary for meeting the needs of the patients of the government health care sector in developing countries.

Thompson (2005) in his study had shown that consumers often misjudge their health risks owing to a number of well-documented cognitive biases. These studies assume that consumers have trust in the expert systems that culturally define safe and risky behaviours. Consequently, this research stream does not address choice situations where consumers have reflexive doubts toward prevailing expert risk assessments and gravitate toward alternative model of risk reductions. This study explores how dissident health risk perceptions are culturally constructed in the natural childbirth community, internalized by consumers as a compelling structure of feeling, and enacted through choices that intentionally run counter to orthodox medical risk management norms.

Due to lack of works regarding this subject in Bangladeshi context the writters aimed to show the result of their survey regarding topic and wish to found workings in future regarding this topic in Bangladeshi context.

\section{OBJeCtive OF THE STUdY}

The present study is based on exploratory and descriptive research design with the objective of measuring the satisfaction level of patients' of private hospitals in Sylhet City.

\section{Methodology of the Study}

The study uses both primary and secondary informa-
tion.This report is prepared by taking into consideration the $50 \%$ hospitals of sylhet city and perception of 50 patients found in those hospitals that time the researcher surveyed and who has previously received health care from those private hospital of Sylhet city. To study patrons' perception, expectations and their satisfaction level it was required to examine the following aspects (I) Patients' perceptions for the manner of the doctors,(II) Patients' perceptions for the manner of the medical assistants, (III) Patients' perceptions for the excellence of administration of hospitals, (IV) Patients' perceptions for the services provided by the hospitals, (V) Patients' expectations from the manner of the doctors, (VI) Patients' expectations from the manner of the medical assistants, (VII) Patients' expectations from the excellence of administration of hospitals, (VIII) Patients' expectations from the services provided by the hospitals, (IX) Patients' satisfaction level for the manner of the doctors, (X) Patients' satisfaction level for the manner of the medical assistants, (XI) Patients' satisfaction level for the excellence of administration of hospitals and (XII) Patients' satisfaction level for the services provided by the hospitals.

\section{Characteristics of the Patients}

Now we are going discuss about the characteristics of people who have received health care from private hospitals. From the given information we can easily determine the type of people who take health care from costly private hospitals.

\section{i. Gender:}

Majority of the patient who has taken health care from private hospitals are women. The number of male patients is relatively low. That is, about $65 \%$ patients are female while another $35 \%$ are male. The reason behind the large number of female patient is that most of the private hospitals are established based on female disease. ii. Age:

The age of the people who have taken health care from these hospitals are limited to between $15 \& 50$ years. $12 \%$ patients are less than 20 years old; $28 \%$ patients are less than 30 years old; $40 \%$ patients are less than 40 years old; and other $20 \%$ patients are less than 50 years old. That is, among the patients young adults are predominant.

\section{iii. Occupation of the family leader:}

By observing the patient or his family leader's occupation, we found that, $65 \%$ are businessman, and other $35 \%$ are service holder. The families whose leaders are Service holder have multiple sources of income out of their job. This is the reason why service holders can afford the health service of expensive private hospitals.

iv. Amount of monthly expenditure:

The amounts of monthly expenditure of service receiver from private hospitals are as given below:

\begin{tabular}{|c|c|}
\hline Monthly expenditure (tk) & Percentage of patients \\
\hline $10000-15000$ & $12 \%$ \\
\hline $15000-20000$ & $18 \%$ \\
\hline $20000-25000$ & $32 \%$ \\
\hline $25000-30000$ & $18 \%$ \\
\hline
\end{tabular}

Page 104 


\begin{tabular}{l|l}
\hline $30000-35000$ & $10 \%$ \\
\hline More than 35000 & $10 \%$ \\
\hline
\end{tabular}

From the above table, we observe that without having strong financial base people can not receive the service of private hospitals.

\section{v. Educational Qualification:}

Those people who receive the service of private hospitals mostly are literate. $55 \%$ of them are graduated and the other $45 \%$ have an educational qualification of either secondary or more. From this we can say that, there is a nexus between education and health consciousness.

\section{Experience and Perception of Patients tOWARDS PRIVATE Hospitals}

The main aim of this report is to find the perception of patients towards the service quality of private hospitals. Patients have given the following data from their experience about private hospitals:

\section{(a) Reasons behind taking health care from Private} Hospitals

1. It is not easy for patients to get admitted in a public hospital.

2. The service quality of public hospital is very poor.

3. The physical environment of public hospital is very dirty.

4. The doctors and nurses of public hospitals are not much careful to patients.

Out of these reasons, some other reasons are there behind taking health care from private hospitals. These reasons are:

- $85 \%$ patients get him/her admitted into a specific private hospital by following the prescription of his/her doctor.

- They want to receive specialized health care.

- Their relatives, friends, colleagues have motivated them to get admitted in private hospitals.

(b) Patient's perception and satisfaction toward Private Hospitals

What patients think of private hospitals? The answer to this question lies in the following points:

1. From their response, it found that, most of the patients think that getting quality service from private hospitals is related with money.

2. $75 \%$ think that they are getting quality service.

3. $40 \%$ patients think that doctors do not hear their words carefully.

4. But about all the patients are satisfied of the service provided by the nurses.

5. $60 \%$ patients give positive response about the foods provided by the hospital; other $40 \%$ think that it is not of good quality.

6. About $85 \%$ patients told that there is no testing laboratory facility in most of the hospital.

7. More than $85 \%$ of the patients are satisfied about the physical environment; other $15 \%$ are dissatisfied.

8. $50 \%$ of the patients think that the service these hospitals are providing and the amount they are charging not reasonable.

We also asked them whether they will suggest others to come to that hospital where he or she was. About half of the patients were provided negative response to this question.

\section{Recommendation}

In order to achieve public satisfaction and to improve the quality of private hospitals, the following things should be done:

1. The treatment expense must be reasonable. That is why the authority of private hospitals must concentrate on service first and then to business.

2. Doctors and nurses have to treat all patients equally.

3. Unnecessary tests, that are given for business purpose only, must be avoided.

4. The price of emergency medicines that they provide in times of emergency situation should be reasonable.

5. There must be entertainment facilities available in the hospital for patients.

6. It is needed to provide health care to people who come from outside.

7. Initiatives should be taken to ensure better health care in order to achieve patient satisfaction.

\section{Conclusion}

The appearance of private hospitals is a reality. Ours is a poor country. It is not possible for our country to provide quality health care service to all. So we have to rely on private hospitals to fulfil our health care need. That is why we have to pay more attention to improve the service quality of private hospitals and the government should monitor the service provided in private hospitals hence no one can deprived. The physical environment is not very bad but each and every hospital should do more to improve the environment quality further. The most important thing these hospitals should charge reasonable amount so that not only financially strong but also financially weak people can get access to the service from these hospitals. This will improve the health situation as well as the profitability of private hospitals in Sylhet City, Bangladesh. If we can make these positive service quality improvements into the private hospitals, we can ensure a healthy society. So, in order to create a healthy Sylhet city, giving emphasis to private hospital service quality improvement is a dire need of time.

\section{REFERENCES}

[1] Sharma R D and Chahal H (1999) A study of patient satisfaction in outdoor services of private health care facilities. Vikalpa 24: 69-76

[2] Sharma R D and Chahal H (2003) Patient satisfaction in government outpatient services in India. Decision30: 109-28.

[3] Hasan, Imrul (2003) Private Hospitals of Bangladesh

[4] Boulding W, Kalra A, Staelin R and Zeithmal VA (1993) A dynamic process model of service quality: from expectations to behavioral intentions. J Mktg 30:7-27

[5] Saha A.K. (1988) Satisfaction with life- A study of nurses Nigeria. Decision 15:61-64

[6] Voss D (1998) Role of price performance and expectation in service. J Mktg Res 36: 45-51

[7] http://www.scribd.com/doc/14816854/customersatisfaction-from-hospital-services-a-study-of-major-privatehospitals-of-ludhiana 